
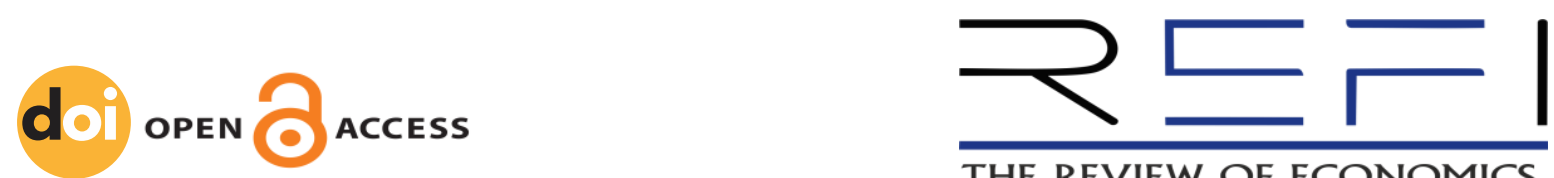

THE REVIEW OF ECONOMICS, FINANCE AND INVESTMENTS

\title{
The Development of Energy Blockchain and Its Implications for the Energy Sector
}

\author{
By MAGDALENA SIKORSKA*
}

\begin{abstract}
Although blockchain technology was initially thought to be dedicated to digital currency applications, the study groups quickly realised its usability that it could be beneficial to various sectors of society, industry, and business, including the sector of electricity. Currently, the European energy sector is in the process of transformation, which is associated with the transition from conventional to renewable energy using the latest technological solutions, also based on blockchain technology. This paper reviews the academic literature and industry practices of the implementation of blockchain in the energy sector. The systematic review by considering two sources is attempting to integrate insights from different bodies of knowledge. The results show that the number of publications about blockchain technology in the energy sector has been skyrocketing, especially since 2017, indicating that combining blockchain technology with the energy sector is a new cross-cutting research area with increasing attention.
\end{abstract}

JEL Classification: E20, O13, Q40.

Suggested citation: Sikorska, M. (2020). The Development of Energy Blockchain and Its Implications for the Energy Sector. The Review of Economics, Finance and Investments, 1(1), 15-23.

\section{INTRODUCTION}

The fourth industrial revolution currently underway, also known as Industry 4.o, is engaging companies in a constant search for technological innovation. Furthermore, global access to ICT networks, As a result, enterprises that want to expand their market share must carry out R\&D activities and use innovative solutions and new technologies (Rymarczyk 2020).

Blockchain tools are one of the most revolutionary technologies of the 21st century. At its core, blockchain is a distributed database of records that enables the development of cryptocurrencies and smart contracts. Transactions stored in the blockchain are irreversible. Any attempt to change one block entails changing the entire subsequent blockchain. A single entity does not operate blockchain as a distributed system. It can therefore be treated as a kind of common infrastructure shared between all participants. Furthermore, such a system does not have a central governing body, so using a system based on blockchain infrastructure facilitates automation and simplifies systems used across multiple companies.

This paper reviews the academic literature and industry practices of the implementation of blockchain in the energy sector. The systematic review by considering two sources is attempting to integrate insights from different bodies of knowledge. This review article aims to compare academic literature and trade publications to understand actual implementation levels and use cases and determine the direction the energy sector is currently heading in terms of adopting blockchain technology. Furthermore, this approach identifies the most common areas of the impression of blockchain technology in the energy sector.

\footnotetext{
* Magdalena Sikorska, Assistant Professor at Podhale State College of Applied Sciences in Nowy Targ (Poland), PhD Student at Cracow University of Economics (Poland); ORCID: 0000-0001-9630-2959; email: magdalena.sikoorska@wp.pl.
} 


\section{LITERATURE REVIEW}

Blockchain as a new technology now offers the possibility to change the way companies operate in a digitally connected ecosystem. These changes are conditioned by the ongoing - as already mentioned - fourth industrial revolution, also referred to as Industry 4.0, which forces companies to seek technological innovation and adapt to business trends constantly. Due to the global ICT network, the effective building of competitive advantage is no longer local. Enterprises that want to deepen their market share must implement research and development activities and use innovative solutions and new technologies.

Blockchain technology, being a distributed register of operations, is one of the technologies of the future. "Blockchain" emerged as a new term with the establishment of bitcoin, which achieved big success after it appeared. Nakamoto (2008) first introduced the blockchain in his paper "Bitcoin: A Peerto-Peer Electronic Cash System." However, a blockchain can exist as a distributed data structure for any cryptocurrency, not necessarily bitcoin. It is generally believed that blockchain and bitcoin will profoundly affect the world (Zhu et al. 2020). Nakamoto's (2008) paper described the idea of new electronic money operating in a completely secure way, without the support of certification authorities and based entirely on a distributed peer-to-peer network. This money was named bitcoin.

Wang \& Su (2020) state that there is currently a lack of systematic review on blockchain's definition and development history in academics, leading to incomplete basic research on blockchain, especially in the energy sector. A blockchain is generally considered a simplified record of operations carried out on a given network, which can be accessed and viewed by all its users. Blockchain technology is therefore used to store and transmit information about transactions made on the internet. These transactions are arranged in the form of consecutive data blocks. Each block contains information on a precisely defined number of transactions. Once it is filled with information about the transactions, another data block is created, followed by another. In this way, a chain is created (the so-called blockchain, or chain of blocks).

It can be assumed that blockchain technology is a constantly updating distributed database. The records in the register are public, so any user can add information to it but cannot change it themselves. Vigna \& Cassey (2018) develop a definition of blockchain as follows. It is a registry of:

- $\quad$ distributed - it is not stored in one place; there is no single "original." Each computer (node) independently updates the register in coordination with other nodes;

- non-backwards modifiable - by definition, only information can be added to it. However, it is possible to modify the register in practice, provided that at least $51 \%$ of nodes agree to it. However, forced backwards modification requires enormous computing power and is connected with the actual destruction of a given blockchain;

- reliably signed using public encryption keys - users have two keys: one is private (works similar to a PIN code), the other is public and linked to valuable information (such as the number of bitcoins held), something like an email address or bank account number.

The use of the private key makes it possible to handle the information in question and send it to the public key of another user;

- $\quad$ sequentially linked and cryptographically secured - individual blocks are linked via indestructible mathematical padlocks into a confirmed chain;

- replicable - the registry is copied by all computers (nodes) participating in the network;

- consensus-based - blockchain uses software that guides all users towards a consensus to harmonise records in the registry. Therefore, any changes to the software require the agreement of at least a majority of users; otherwise, the blockchain may fork, and separate versions of the registry may be created.

Numerous studies show that blockchain improves transparency (Sunny et al. 2020; Kittipanyangam \& Tan 2020) and data traceability (Qian et al. 2020; Rejeb 2018; Tan et al. 2020). Furthermore, some studies positively impact company performance (Kamble et al. 2020) and new business models (Weking et al. 2020). Blockchain technology can be applied in many areas of life, such as agriculture (Bermeo-Almeida et al. 2018), healthcare (McGhin et al. 2019), construction (Li et al. 2019), food (Tian 2016), logistics (Tijan et al. 2019), finance (Sivaram et al. 2020) or education (Alammary et al. 2019). 
Over the past few years, the application areas of blockchain have diversified. One example is the energy sector, which, as a traditional heavy industry, faces new challenges caused by distributed energy and information technology development. Therefore, blockchain also has a deep and practical application basis in the energy field. With the transformation of the energy sector, research on blockchain applications in the energy field is increasing (Wang et al. 2021; Ahl et al. 2020; Andoni et al. 2019; Talat et al. 2020; Kim \& Huh 2018; Mengelkamp et al. 2018; Sawa 2019; Wang et al. 2019; Troncia et al. 2019). In addition, numerous pilot projects demonstrate that blockchain technology in the energy market can make sense, especially concerning prosumers and microgrid applications.

\section{DATA AND RESEARCH METHODOLOGY}

This study undertook a systematic literature review in this research by reviewing two literature sources. The first literature source is Scopus, which mainly focuses on academic literature. The second literature source deals with energy industry reports, trade publications, and reviewed news articles. The EBSCOHOST database will be used to review this literature. Connecting these two sources of information is important for researching emerging technologies such as blockchain (Ahmed et al., 2019). The systematic literature review helps us track the progress of the subject matter and identify the themes that have emerged over time. In addition, it gives the bigger picture across the globe in terms of challenges, opportunities, and characteristics. (Hart, 2018).

\subsection{Literature selection from Scopus}

Scopus is one of the most popular and comprehensive databases for scientific articles in engineering, business, and social sciences for literature reviews (Grower et al., 2019).

The initial search article used was "blockchain" and "energy sector" under "Title, abstract and keywords." The search resulted in 200 documents. Considering the volume of the results, the search was limited only to journal articles, which amounted to 88 articles. After this, the keywords were limited to "blockchain, energy, application." This refined the search results to 42 articles (Fig.1.)

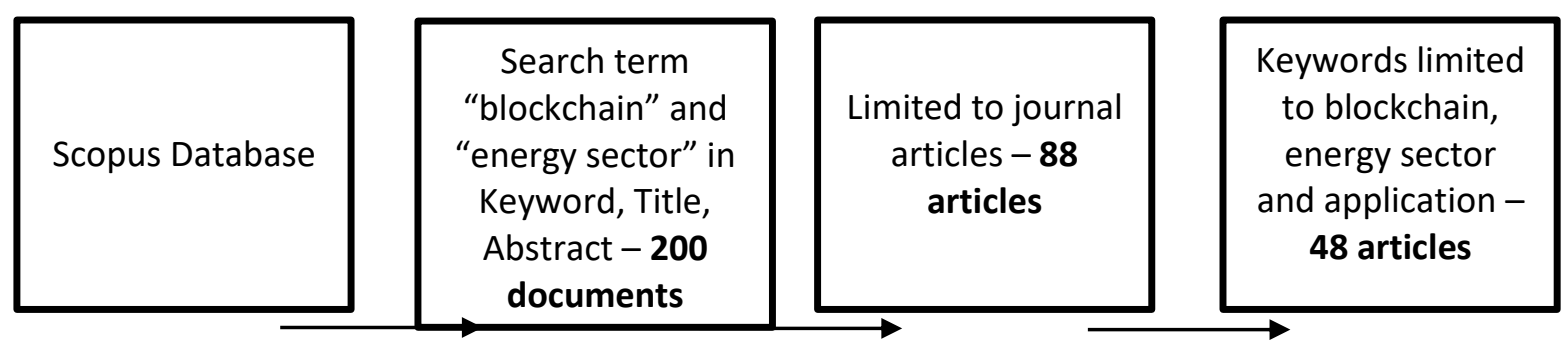

Fig. 1. Stages for selection of academic articles for literature review.

\subsection{Literature selection from EBSCOHOST trade literature}

The initial search combination which was used is "blockchain" and "energy sector" under Titles, which resulted in 36 articles. Since the aim is to focus only on industrial practices, the search results were filtered only to trade publications, news articles, and magazines, resulting in 21 articles. Most of the articles explained the use cases already implemented in the industry, thus giving us insights into the actual implementation (Fig.2.). 


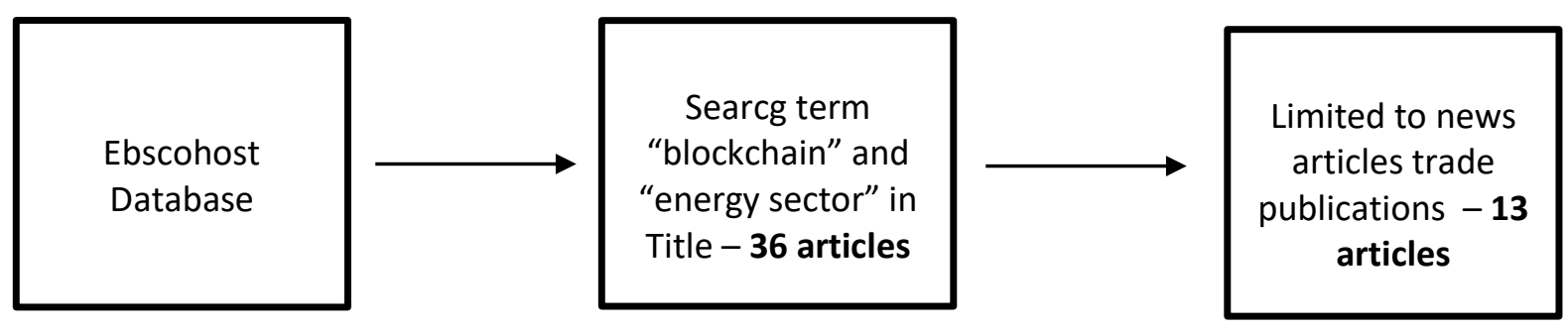

Fig.2. Stages for selection of trade articles for literature review.

After the analysis, it can also be concluded that the number of articles published in academic and trade publications had an upward trend from 2017 to 2020 (Fig.3.). This analysis enabled identifying the most popular opportunities for implementing blockchain technology into the energy sector described later in this paper.

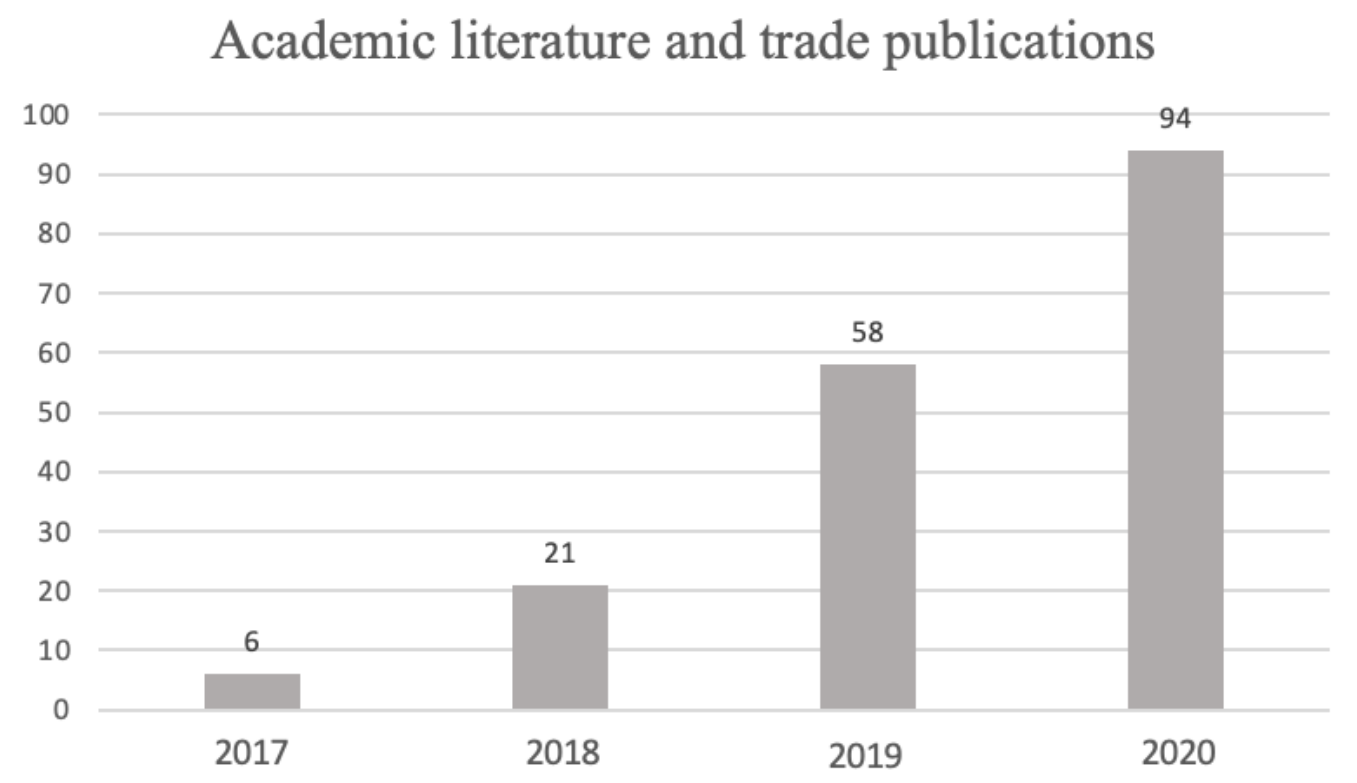

Fig.3. The number of articles published between 2017 and 2020.

\section{EMPIRICAL ANALYSIS - RESULTS AND DISCUSSION}

This section aims to provide an overview of the core value propositions from our two sources of information and combine them to explore how blockchain has been used in the industry.

\subsection{Blockchain potential and notable use cases in energy applications}

The current state of the Polish energy sector and its future and development directions are some of the key issues in the contemporary economy. Political and social aspirations change the traditional system of functioning of energy enterprises and influence the necessity of implementing innovative processes in the Polish energy sector. New directions of development and changes occurring in the Polish energy sector should, on the one hand, ensure energy security in the country; on the other hand, they become a necessary condition for the growth of competitiveness of the sector and allow to meet multidimensional challenges at the national, European and global levels.

Dynamic changes in the energy market mean that solutions based on the blockchain can bring significant benefits and savings. Furthermore, widespread changes in the models of both energy pro- 
duction (from renewable sources) and its consumption (through the development of the prosumer market and electromobility) will mean that the flexibility and innovation of the offered solutions and a deep understanding of the directions of changes in the energy sector will determine the future shape of the activities of prominent players in this market. Analysing the energy market and drawing conclusions from the systematic literature review, one can notice that most of the activities concern the following applications.

\section{- Development of microgrids and smart grids}

An electricity microgrid is a system of electricity generating equipment, energy storage facilities, and loads that form a common grid to ensure reliable electricity supply in the immediate region and to minimise the cost of procuring electricity in other ways. A micro-grid is made up of micro renewable energy sources and conventional sources and energy consumers and storage (batteries, supercapacitors, etc.), working as a single unit near each other to supply electrical energy (Matusiak 2013) optimally.

Producers, consumers, and prosumers (who simultaneously produce and consume electricity) as microgrid participants can settle with each other and/or with the microgrid environment using tokens/cryptocurrencies. The realised payments and settlements of the blockchain network are fast, available to all participants, and performed automatically and without involving intermediaries. Creating a settlement system based on blockchain technology will enable the settlement of microgrids dynamically and automatically. To describe the process as fully automated, it should be integrated with smart electricity meters (which allow electricity consumption information to be automatically stored and sent wirelessly to the energy provider).

\section{- Wholesale energy market}

Electricity is a commodity that is usually traded on exchanges, with the wholesale energy market being the primary tool for this purpose. Thus, its users are large producers and wholesale buyers. Theoretically, direct customers could participate in this market but are prevented from doing so by the high participation costs, including market access charges, the need to maintain an IT infrastructure, and staff costs.

Reducing the cost of participation could positively impact the market as it would improve liquidity, affect the commitment of small-scale renewable generators, increase competition, and improve the flexibility of supply. In addition, the higher capacity of the trading platform could have an impact on shortening the time slots for procuring electricity. According to the rules adopted by participants, blockchain technology could become a tool to improve the wholesale market through settlements implemented through cryptocurrencies or cryptocurrency tokens and the implementation of a trading platform through a smart contract, ensuring that trading takes place in a decentralised manner.

\section{- Emissions trading}

The purpose of the emission allowance trading market is to transfer for consideration between participants documents purchased or received from an issuer confirming entitlement to release a certain quantity of environmentally harmful substances into the environment.

Trading costs are relatively high due to the closed market and a small number of participants. Tools of blockchain technology could support the emissions trading mechanism. For example, cryptocurrency tokens could be used for implementation. Blockchain technology can ensure lower trading costs by eliminating intermediaries. The trading market could be organised based on a blockchain network managed by a consortium consisting of all or only key trading participants. A cryptocurrency token would be created in the network, the power to issue would be granted to a supervisory authority. This authority would be a guarantor of the token's value and the reliability of its issue and redemption.

\section{- Electromobility}

The development of the electromobility market is also important for the future of the energy sector. An argument in favor of introducing e-mobility into the strategic activities of energy companies is 
the gradual creation of appropriate legal regulations and the growing interest in environmentally friendly products and solutions.

The cost of charging an electric car is important for the further development of electromobility. This varies depending on where one lives, the electricity supply price, or the charging point itself. The use of blockchain technology would enable the elimination of financial intermediaries, which would make the price of electricity lower than if payment methods offered by banks were used. Blockchainbased payments could be made unattended, if necessary, which would combine perfectly with automated charging stations performing their service without unnecessary user attention. Charging station users could make payments via blockchain, for example, using cryptocurrencies or cryptocurrency tokens.

\section{- Certificate of Origin Register}

A certificate of origin register is a document that confirms that electricity was produced from renewable energy sources. It is also called a certificate of origin or so-called green certificate. Due to environmental protection and the need to change the structure of electricity production, green certificates are one way to stimulate the renewable energy sources market. Entities with a statutory obligation to partially or exclusively use renewable energy, or entities that want to use renewable energy for marketing and image purposes, are interested in purchasing certificates.

The current certification system consists of many steps and involves many intermediaries. The complexity of the process decreases credibility and increases costs, wiping out much of the benefit of certificates. A practical tool to address some of the flaws in the current system is blockchain technology. The best solution would be based on electricity meters installed at green energy producers. These meters would record the parameters of produced energy in the blockchain and create certificates in the form of cryptocurrency tokens. The tokens could carry information about the source from which the energy was generated. The tokens could be traded on the principles developed by cryptocurrency trading markets.

\subsection{Opportunities and risks for blockchain in the energy sector}

To better assess the strengths and weaknesses of blockchain technology and the opportunities and threats it brings, a strategic SWOT analysis was performed. The categories of strengths of distributed ledger technology include (Boniecki \& Rawłuszko 2017):

- non-repudiation of transactions,

- transparency of operations,

- ability to conduct transactions on a global scale,

- increase in public confidence in conducting business on an international scale,

- increase in speed of execution of transactions,

- high innovation potential for further development,

- another stage of moving business to the digital world (smart contracts).

In turn, when analysing the weaknesses of blockchain technology, the most important ones include:

- restriction of the confidentiality of commercial contracts,

- easy creation of speculative bubbles,

- a radical, constant increase in demand for system resources in user nodes (for verification calculations, one has to remember the history of all transactions made in the network)

- lack of protection of users against accidental errors, e.g., recording the transaction address,

- lack of clarity of the legal and tax situation of participants in the blockchain network.

Opportunities generated by distributed registry technology include:

- extension of applications to other spheres of social and economic life,

- creation of further cryptocurrencies,

- building other networks using distributed ledger technology,

- creating a shared distributed ledger with user access only to his part,

- creating a legal environment to support the development of distributed registry technology. 
In addition to the strengths, weaknesses, and opportunities of distributed registry technology, the following risks are also mentioned:

- the increase in computational requirements threatens to drastically reduce the teams of diggers (people who collect cryptocurrency), thus increasing the risk of monopolisation by groups with less public trust;

- with the sudden increase in the number of transactions, there is an increased risk that the diggers will work "on themselves," overlooking certain transactions or groups of transactions in verification.

\section{CONCLUDING REMARKS}

Blockchain as new technology enables companies to function better in the digital ecosystem. The fourth industrial revolution conditions changes in the external environment also referred to as Industry 4.0, which forces companies to seek technological innovation and adapt to business trends constantly. Due to the global ICT network, the effective building of competitive advantage is no longer local. Enterprises that want to deepen their market share must implement research and development activities and use innovative solutions and new technologies.

The benefits of blockchain technology depend primarily on its use in the economy and requires proper financial analysis. It may turn out that the scale of benefits resulting from the use of blockchain tools is small because it concerns systems with a small number of users or those maintained internally. The greatest financial benefits of using blockchain technology relate mainly to systems with a national or international scope. Then blockchain makes it possible to reduce transaction costs and reduce departments responsible for settlements significantly.

An exciting example showing the increasing use of blockchain tools is the area of energy and commodity companies. Attempts to use blockchain to solve various problems can be seen in large energy producers, small companies, and startups. Analysing academic literature, energy industry reports, trade publications, and reviewed news articles, one can see the application of blockchain tools in the areas of microgrids, the wholesale energy market, electromobility, $\mathrm{CO} 2$ emissions trading, or the system of trading certificates of origin of energy. However, in addition to the energy sector, many other industries are conducting tests and proposing pilot solutions based on blockchain tools, showing increasingly secure and cheaper use of this technology.

\section{REFERENCES}

Ahl, A., Yarime, M., Goto, M., Chopra, S. S., Kumar, N. M., Tanaka, K., \& Sagawa, D. (2020) Exploring blockchain for the energy transition: Opportunities and challenges based on a case study in Japan. Renewable and Sustainable Energy Reviews, 117, 109488.

Ahmed, Y. A., Ahmad, M. N., Ahmad, N., \& Zakaria, N. H. (2019) Social media for knowledge-sharing: A systematic literature review. Telematics and informatics, 37, 72-112.

Alammary, A., Alhazmi, S., Almasri, M., \& Gillani, S. (2019) Blockchain-based applications in education: A systematic review. Applied Sciences, 9(12), 2400.

Andoni, M., Robu, V., Flynn, D., Abram, S., Geach, D., Jenkins, D., McCallum P., Peacock, A. (2019) Blockchain technology in the energy sector: A systematic review of challenges and opportunities. Renewable and Sustainable Energy Reviens, 100, 143-174.

Bermeo-Almeida, O., Cardenas-Rodriguez, M., Samaniego-Cobo, T., Ferruzola-Gómez, E., Cabezas-Cabezas, R., \& Bazán-Vera, W. (2018) Blockchain in agriculture: A systematic literature review. In International Conference on Technologies and Innovation (pp. 44-56). Springer, Cham.

Boniecki R., \& Rawłuszko J. (2017) Mozliwości wykorzystania technologii Blockchain w biznesie. Ekonomične Problemy Ustug.

Casey, M. J., \& Vigna, P. (2018) The truth machine: the blockchain and the future of everything. St. Martin's Press.

Grover, P., Kar, A. K., \& Janssen, M. (2019) Diffusion of blockchain technology. Journal of Enterprise Information Management.

Hart, C. (2018). Doing a literature review: Releasing the research imagination.

Kamble, S. S., Gunasekaran, A., \& Gawankar, S. A. (2020) Achieving sustainable performance in a data-driven agriculture supply chain: A review for research and applications. International Journal of Production Economics, 219, 179-194.

Kim, S. K., \& Huh, J. H. (2018) A study on the improvement of smart grid security performance and blockchain smart grid perspective. Energies, 11(8), 1973.

Kim, Y. M., Jung, D., Chang, Y., \& Choi, D. H. (2019) Intelligent micro energy grid in 5G era: Platforms, business cases, tes tbeds, and next generation applications. Electronics, 8(4), 468.

Kittipanya-Ngam, P., \& Tan, K. H. (2020) A framework for food supply chain digitalization: lessons from Thailand. Production Planning \& Control, 31(2-3), 158-172. 
Li, J., Greenwood, D., \& Kassem, M. (2019) Blockchain in the built environment and construction industry: A systematic review, conceptual models and practical use cases. Automation in Construction, 102, 288-307.

Matusiak B.E. (2013) Modele biznesowe na nowym zintegrowanym rynku energii. Wydawnictwo Uniwersytetu Łódzkiego. Łódź.

McGhin, T., Choo, K. K. R., Liu, C. Z., \& He, D. (2019) Blockchain in healthcare applications: Research challenges and opportunities. Journal of Network and Computer Applications, 135, 62-75.

Mengelkamp, E., Gärttner, J., Rock, K., Kessler, S., Orsini, L., \& Weinhardt, C. (2018) Designing microgrid energy markets: A case study: The Brooklyn Microgrid. Applied Energy, 210, 870-880.

Nakamoto, S. (2019) Bitcoin: A peer-to-peer electronic cash system. Manubot.

Qian, J., Dai, B., Wang, B., Zha, Y., \& Song, Q. (2020) Traceability in food processing: problems, methods, and performance evaluations_-a review. Critical Reviews in Food Science and Nutrition, 1-14.

Rejeb, A. (2018) Halal meat supply chain traceability based on HACCP, blockchain and internet of things. Acta Technica Jaurinensis, 11(1).

Rymarczyk, J. (2020) Technologies, Opportunities and Challenges of the Industrial Revolution 4.0: Theoretical Considerations, Entrepreneurial Business and Economics Review, 8(1), s.185-198.

Sawa, T. (2019) Blockchain technology outline and its application to field of power and energy system. Electrical Engineering in Japan, 206(2), 11-15.

Shankar, K. (2020) An optimal least square support vector machine based earnings prediction of blockchain financial products. IEEE Access, 8, 120321-120330.

Talat, R., Muzammal, M., Qu, Q., Zhou, W., Najam-ul-Islam, M., Bamakan, S. H., \& Qiu, J. (2020) A decentralized system for green energy distribution in a smart grid. Journal of Energy Engineering, 146(1), 04019036.

Tan, A., \& Ngan, P. T. (2020) A proposed framework model for dairy supply chain traceability. Sustainable Futures, $2,100034$.

Teufel, B., Sentic, A., \& Barmet, M. (2019) Blockchain energy: Blockchain in future energy systems. Journal of Electronic Science and Technology, 17(4), 100011

Tian, F. (2016) An agri-food supply chain traceability system for China based on RFID \& blockchain technology. In 201613 th international conference on service systems and service management (ICSSSM) (pp. 1-6). IEEE.

Tijan, E., Aksentijević, S., Ivanić, K., \& Jardas, M. (2019) Blockchain technology implementation in logistics. Sustainability, 11(4), 1185.

Troncia, M., Galici, M., Mureddu, M., Ghiani, E., \& Pilo, F. (2019) Distributed ledger technologies for peer-to-peer local markets in distribution networks. Energies, 12(17), 3249.

Wang, Q., \& Su, M. (2020) Integrating blockchain technology into the energy sector-from theory of blockchain to research and application of energy blockchain. Computer Science Review, 37, 100275.

Wang, Q., Li, R., \& Zhan, L. (2021) Blockchain technology in the energy sector: From basic research to real world applications. Computer Science Review, 39, 100362.

Wang, S., Taha, A. F., Wang, J., Kvaternik, K., \& Hahn, A. (2019) Energy crowdsourcing and peer-to-peer energy trading in blockchain-enabled smart grids. IEEE Transactions on Systems, Man, and Cybernetics: Systems, 49(8), 1612-1623.

Weking, J., Mandalenakis, M., Hein, A., Hermes, S., Böhm, M., \& Krcmar, H. (2019) The impact of blockchain technology on business models-a taxonomy and archetypal patterns. Electronic Markets, 1-21.

Zhu, S., Song, M., Lim, M. K., Wang, J., \& Zhao, J. (2020) The development of energy blockchain and its implications for China's energy sector. Resources Policy, 66, 101595. 
CONFLICT OF INTEREST:

The authors declare that they have no material or financial interests associated with the research presented in this article. The authors declare that the study was conducted in the absence of any commercial or financial relationship giving rise to a conflict of interest.

\section{COPYRIGHT AND LICENSE:}

\section{(c) (1) $\Theta$}

This article is published under the terms of the Creative Commons

Attribution - NoDerivs (CC BY-ND 4.0) License

http://creativecommons.org/licenses/by-nd/4.o/

Published by Podhale State College of Applied Sciences - Nowy Targ, Poland 